\title{
VISUAL OBSERVATION OF FOAMING AT THE BATCH-MELT INTERFACE DURING MELTING OF SODA-LIME-SILICA GLASS
}

\author{
JAROSLAV KLOUŽEK*,**, PETRA CINCIBUSOVÁ*,** MIROSLAVA VERNEROVÁ****, \\ JOSE MARCIAL*,**, PAVEL HRMA***, "RICHARD POKORNÝ*,** \\ *Laboratory of Inorganic Materials, University of Chemistry and Technology Prague, Prague 6, 166 28, Czech Republic \\ **Institute of Rock Structure and Mechanics, Czech Academy of Sciences, Prague 8, 182 09, Czech Republic \\ ***AttainX, Support Services Contractor to the Office of River Protection, U.S. Department of Energy, Richland, WA, USA
}

\#E-mail: richard.pokorny@vscht.cz

Submitted August 16, 2021; accepted October 30, 2021

\begin{abstract}
Keywords: Batch melting, Batch foaming, Foam decay, Visual observation
One of the least understood phenomena related to the optimization of the batch-to-glass conversion in melters is the behavior of the primary foam layer that develops at the interface between the batch and melt. Although its structure and behavior are directly linked with the heat and mass transfer between the reacting batch and melt, until recently, the foam layer at the batch bottom has eluded direct measurement. In this work, we build on our previous research addressing the primary foam behavior using high-temperature in-situ visual observation, and analyze its behavior at the batch-melt interface during melting of representative container soda-lime-silica glass. We visualize the formation of primary foam and its coalescence and collapse, leading to the formation of gas cavity layer at the batch bottom. The unprecedent contrast and resolution of the images provides detailed information on the foam morphology during melting, and can help in future development of more realistic batch melting models.
\end{abstract}

\section{INTRODUCTION}

Despite the long tradition of the glass melting technology, which spans almost two centuries of research and development [1], numerous opportunities still exist to improve the efficiency of the manufacturing process. However, due to the abundance of unanswered fundamental questions in the field of kinetics and thermodynamics of glass batch melting, these opportunities often cannot be explored or are not utilized to their full potential. For example, Mauro et al. [2] recently compiled a list of nearly 100 open questions in different areas of glass research, showing ample room for new breakthroughs both in fundamental science and industrial applications. With respect to the glass-melting technology itself, one of the least understood phenomena are the various processes occurring directly in the mel-ting batch (Figure 1). These phenomena are numerous and complex, from the batch reactions producing early glassforming melt [3-5], dissolution of solids, mainly silica $[6,7]$, and the evolution, growth, and collapse of primary foam [8-11].

The aim of this work is to address some of these phenomena, specifically, to evaluate the structure and behavior of the foam layer at the interface between the batch and melt. Unlike other batch-melting processes, primary foam behaves differently in laboratory crucibles than at the bottom of the batch in a glass melting furnace [12]. In laboratory experiments, the foam can expand unobstructed, gases are continuously released from the foaming batch into the atmosphere, and the primary and secondary foaming can overlap [13]. At the bottom of the batch in a glass-making furnace, primary foam bubbles are trapped inside the glass-forming melt, growing and coalescing, until eventually collapsing into cavities, large flat bubbles that form at the batch bottom. These cavities move horizontally until they find a way to escape at the batch layer edge through the melt free surface [14].

Nevertheless, following the recent literature showcasing the importance of primary foam behavior for the evaluation of heat transfer to the batch [11], a number of studies has been performed, providing significant new insights into the primary foam structure at the batch-melt interface and on the kinetics of foaming. These studies include (i) high-temperature visual observation and later also in-situ x-ray tomography evaluating the foam volume, porosity, bubble size distribution, and analysis of the foam coalescence and collapse [12, 15-17], and (ii) kinetic studies analyzing how the temperature interval of primary foaming and the foam structure depend on the batch thermal history [18-20]. These studies mostly focused on the foam behavior during melting of simulated nuclear waste feeds. Here, we complement them by performing high-temperature visual observation (HTVO) of foam behavior at the batch-melt interface for a typical soda-lime-silica container glass batch. To characterize the gas evolution during foaming, the HTVO experiments are supported by thermogravimetric and evolved gas analyses. 
Until recently, the foam morphology at the bottom of the batch layer has eluded direct measurement [17]. The results obtained in this work provide a clear information about the foam behavior during melting of container glass batch. Moreover, because the behavior of foam is directly linked to the heat and mass transfer between the batch and melt, the results of this work can help in future development of more realistic batch melting models $[21,22]$.

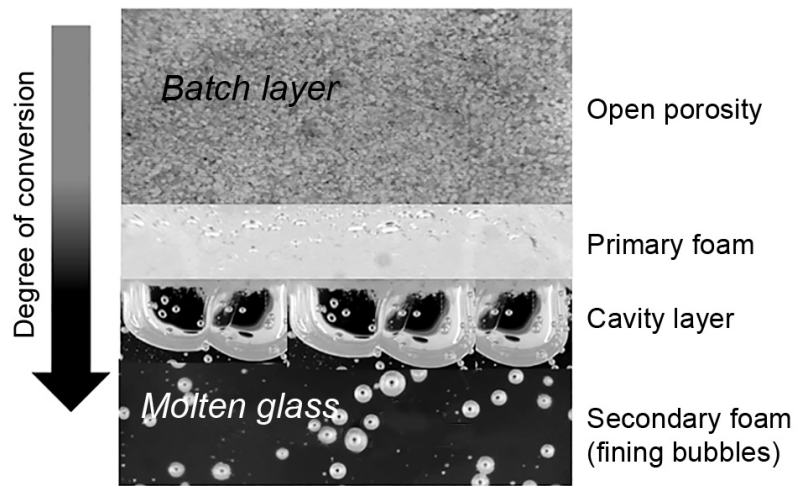

Figure 1. Schematic illustration of the interface between batch layer and molten glass. Primary foam is produced when gases from batch conversion reactions are trapped in the glassforming melt. Secondary bubbles are formed from fining reactions in the melt. Below the batch layer, cavities are formed by the coalescence and collapse of primary foam bubbles and by the ascending secondary bubbles.

\section{EXPERIMENTAL}

\section{Batch composition}

Table 1 lists the composition of batches to make a container glass, whose composition is listed in Table 2. Batch \#1 is a prototypical batch, the melting of which was experimentally characterized in great detail in our previous study [19]. In the second batch (B\#2), feldspar is substituted with sand, potash, aluminum hydroxide, and magnesium oxide to make it possible to prepare batch pellets for the visual observation experiments.

Table 1. Composition of $\mathrm{B} \# 1$ and $\mathrm{B} \# 2$ batches in $\mathrm{g}$ to make $100 \mathrm{~g}$ of glass.

\begin{tabular}{lrr}
\hline & $\begin{array}{c}\text { Batch 1 } \\
(\mathrm{B} \# 1)\end{array}$ & $\begin{array}{c}\text { Batch 2 } \\
(\mathrm{B} \# 2)\end{array}$ \\
\hline Sand $\left(\mathrm{SiO}_{2}\right)$ & 62.00 & 72.50 \\
Feldspar $\left(\mathrm{Na}\left(\mathrm{K}_{2}\right) \mathrm{AlSi}_{3} \mathrm{O}_{8}\right)$ & 13.49 & 0.00 \\
Limestone $\left(\mathrm{CaCO}_{3}\right)$ & 20.33 & 20.33 \\
Soda ash $\left(\mathrm{Na}_{2} \mathrm{CO}_{3}\right)$ & 21.84 & 21.84 \\
$\mathrm{MgO}$ & 0.00 & 0.80 \\
Potash $\left(\mathrm{K}_{2} \mathrm{CO}_{3}\right)$ & 0.00 & 1.33 \\
$\mathrm{Al}(\mathrm{OH})_{3}$ & 0.00 & 2.24 \\
$\mathrm{Na}_{2} \mathrm{SO}_{4}$ & 0.39 & 0.39 \\
Petroleum coke $(\mathrm{C})$ & 0.04 & 0.04 \\
\hline Total $(\mathrm{g})$ & 118.09 & 119.47 \\
\hline
\end{tabular}

Table 2. Container glass composition.

\begin{tabular}{lc}
\hline Component & Mass (wt. \%) \\
\hline $\mathrm{SiO}_{2}$ & 72.33 \\
$\mathrm{Al}_{2} \mathrm{O}_{3}$ & 1.59 \\
$\mathrm{CaO}$ & 11.20 \\
$\mathrm{MgO}$ & 0.86 \\
$\mathrm{~K}_{2} \mathrm{O}$ & 0.90 \\
$\mathrm{Na}_{2} \mathrm{O}$ & 12.90 \\
$\mathrm{SO}_{3}$ & 0.22 \\
\hline Total & 100 \\
\hline
\end{tabular}

Feed expansion tests (FET)

The FET measures the batch (or "feed") volume and porosity as a function of temperature [23]. The sample is placed on an alumina plate in the furnace, either as a 1.5-g loose-batch cone or a 1.0-g pellet, $13 \mathrm{~mm}$ in diameter and $\sim 6 \mathrm{~mm}$ thick, compressed at $28 \mathrm{MPa}$ for $2 \mathrm{~min}$. The samples are heated from room temperature to $1500{ }^{\circ} \mathrm{C}$ at $10 \mathrm{~K} \cdot \mathrm{min}^{-1}$. The sample profile is monitored with a CCD camera, and the profile area is used to evaluate the sample volume by the method of cylinders of a trapezoidal cross-section implemented in NIS Elements ${ }^{\circledR}$ software (Laboratory Imaging, Czech Republic). Integrated volumes were normalized to the final glass volume, $V_{G}=\left(m_{\text {feed }} / \rho_{\text {glass }}\right)(1-$ LOI $)$, where LOI is the feed mass loss on ignition, $m_{\text {feed }}$ is the feed mass, and $\rho_{\text {glass }} \approx 2.5 \mathrm{~g} \cdot \mathrm{cm}^{-3}$ is the molten glass density. FET experiments were performed in triplicate for error analysis. The foam onset temperature, $T_{F O}$, is obtained from FET as the temperature of minimal feed volume before feed expands due to foaming, while $T_{F M}$ corresponds to the temperature of maximum foam volume.

Thermal gravimetry (TGA)

and evolved gas analysis (EGA)

For TGA (QMS 403C, NETZSCH), 1.5-g batch samples were heated in alumina crucibles $18 \mathrm{~mm}$ in diameter and $20 \mathrm{~mm}$ high from ambient temperature $\left(\sim 25^{\circ} \mathrm{C}\right)$ to $1500^{\circ} \mathrm{C}$ at $2,5,10,20$, and $40 \mathrm{~K} \cdot \mathrm{min}^{-1}$. The EGA was performed using a gas chromatograph with a mass spectrometric detector (Agilent 6890N/5973N), connected to the exhaust line of a silica glass tube furnace [24]. A 1-g loose batch samples were heated from room temperature to $1500{ }^{\circ} \mathrm{C}$ at $10 \mathrm{~K} \cdot \mathrm{min}^{-1}$ under He carrier gas flowing at $50 \mathrm{ml} \mathrm{min}^{-1}$. EGA was used to measure the release rate of $\mathrm{CO}_{2}, \mathrm{CO}$, and $\mathrm{SO}_{2}$; the used setup is not suitable for the analysis of water vapor because the vapor condenses on tube walls.

\section{High-temperature visual observation}

Figure 2 illustrates the setup for the high-temperature visual observation (HTVO). A tailor-made observation cells with rectangular bottom $(30 \mathrm{~mm}$ wide and 
$10 \mathrm{~mm}$ thick) were used to provide high-contrast images. Loose powder batch B\#1 has been tested initially, but the results were not satisfactory - the powder batches (both $\mathrm{B} \# 1$ and $\mathrm{B \# 2)}$ spread across the whole melt surface, leading to gas accumulation below the batch and batch bridging. During a steady-state melting process, a part of the melt surface must remain free of the batch to allow gas bubbbles to escape from below the batch into the atmosphere, avoiding a gas phase buildup. Also, when charging loose powder into the observation vessel, batch particles adhered to the vessel walls, obscuring visual observation. To circumvent this issue, $\mathrm{B} \# 2$ pellets were used for the HTVO, allowing us to replicate the steadystate melting conditions.

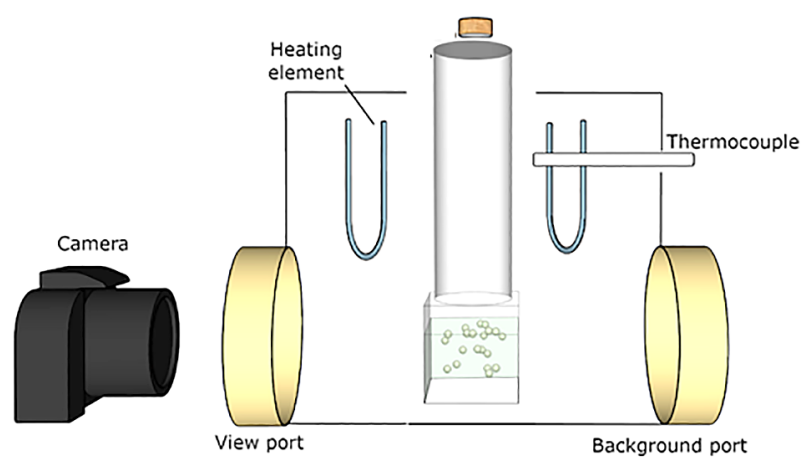

Figure 2. Schematic drawings of visual observation of foaming at the feed-melt interface using rectangular silica glass vessels.

Glass cullet was pre-melted in the silica glass vessels at $1350{ }^{\circ} \mathrm{C}$ to produce melt surface onto which the pellets were manually dropped through the top of the cuvette (the contact angle between the dropped pellet and the melt surface was not controlled). Images were acquired through a view port on the front of the furnace. A second port in the back of the furnace provided a dark cold background to minimize the effect of the light emitted by the furnace refractory at elevated temperatures, which would reduce the image contrast. The camera resolution was 23 pixels per $\mathrm{mm}$ and the minimum size of resolvable features equaled to $140 \mu \mathrm{m}$.

During a steady-state glass melting process, reaction gases that evolve below the foam onset temperature, $T_{F O}$, escape through the feed into the atmosphere above. Thus, only the fraction of gases released above $T_{F O}$ causes the primary foaming at the batch-melt interface. To better replicate the primary foam structure and dynamics, we investigated also the behavior of feed pellets preheated to temperatures around $T_{F O}$.

\section{RESULTS \\ TGA and EGA}

Figure 3 displays the TGA mass fraction, $f_{\text {mass }}=$ $=m(T) / m_{0}$, where $m(T)$ is the sample mass at $T$ and $m_{0}$ is the initial sample mass, and the mass-loss (or gas evolution) rate, $-d f_{\text {mass }} / d_{T}$, measured for the $\mathrm{B} \# 1$ and $\mathrm{B} \# 2$ batches at heating rate $10 \mathrm{~K} \cdot \mathrm{min}^{-1}$. Figure 4 shows the evolution rates of $\mathrm{CO}_{2}, \mathrm{CO}$, and $\mathrm{SO}_{2}$ measured by EGA.

The mass loss observed for batch B\#2 at $\sim 300{ }^{\circ} \mathrm{C}$ corresponds to the release of water from $\mathrm{Al}(\mathrm{OH})_{3}$. The distinct peaks around $400{ }^{\circ} \mathrm{C}$ correspond to the limestone decrepitation and the corresponding $\mathrm{H}_{2} \mathrm{O}$ evolution from the microscopic liquid inclusions within limestone [25], followed by the decomposition of carbonates and their reactions with silica above $\sim 700{ }^{\circ} \mathrm{C}$, producing $\mathrm{CO}_{2}$. Differences between $\mathrm{B} \# 1$ and $\mathrm{B} \# 2$ batches are small, corresponding to the minor changes in $\mathrm{B} \# 1$ and B\#2 compositions (i.e., the gibbsite water content).

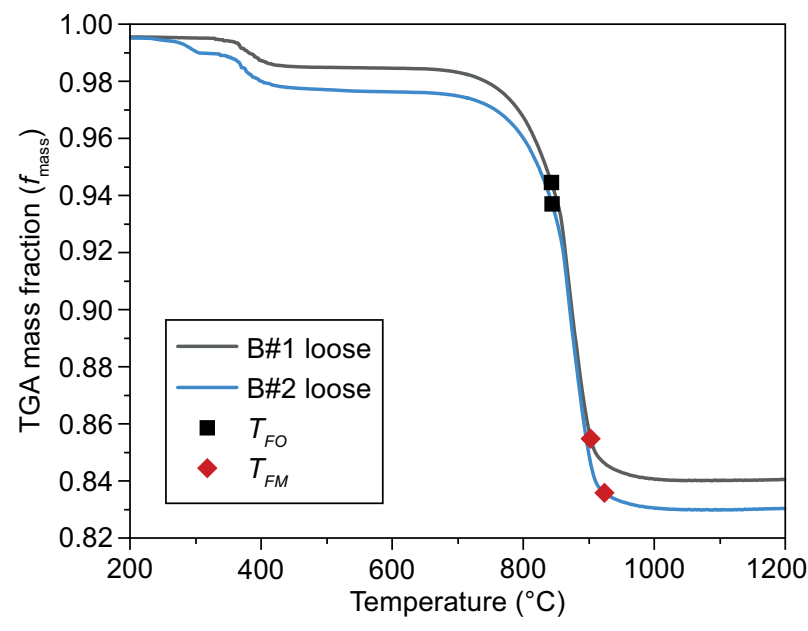

a)

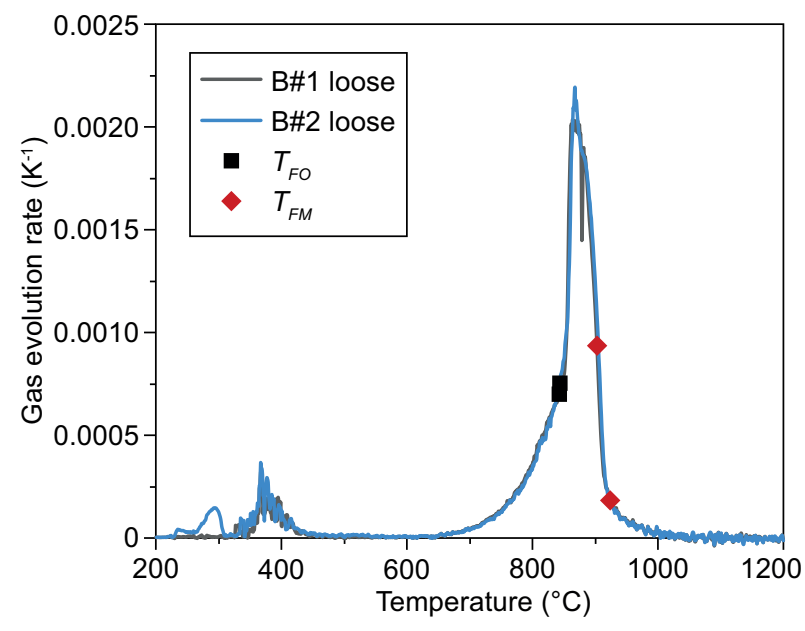

b)

Figure 3. TGA mass fraction $\left(f_{\text {mass }}\right)(\mathrm{a})$, and gas evolution rate (b) versus temperature at heating rate $10 \mathrm{~K} \cdot \mathrm{min}^{-1}$. The square and diamond open points mark $f_{\text {mass }}$ and gas evolution rate values at the foam onset $\left(T_{F O}\right)$ and foam maximum $\left(T_{F M}\right)$ temperatures, respectively. 


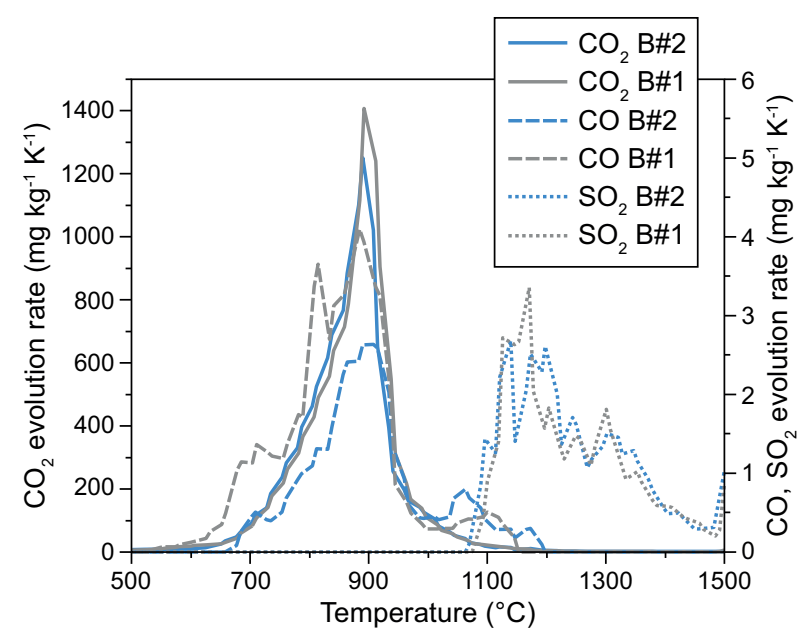

Figure 4. $\mathrm{CO}_{2}, \mathrm{CO}$, and $\mathrm{SO}_{2}$ evolution rates versus temperature at heating rate $10 \mathrm{~K} \cdot \mathrm{min}^{-1}$.

\section{Feed expansion tests (FET)}

Figure 5 shows profile images of $\mathrm{B} \# 1$ and $\mathrm{B} \# 2$ loose batches and $\mathrm{B} \# 2$ pellet heated at $10 \mathrm{~K} \cdot \mathrm{min}^{-1}$. Figure 6 displays the normalized volume $\left(V / V_{G}\right)$ as a function of temperature and heating rate, where $V_{G}$ is the bubblefree glass-melt volume.

As the samples were heated, limestone decrepitation caused slight flattening of the loose batch cones at $\sim 300{ }^{\circ} \mathrm{C}$, but their normalized volume remained almost constant; limestone decrepitation also did not visibly affect the shape or volume of the pressed pellet. The oscillations of the loose batch $V / V_{G}$ curves, observed below the foaming onset temperature (according to Figure $6, T_{F O} \cong 840{ }^{\circ} \mathrm{C}$ for all samples), are caused by a somewhat larger uncertainty in the volume of loose batch samples due to less defined profile outlines. The pellet is more axially symmetrical than loose batch cones and its outline can be tracked with a higher accuracy. However, pellets cannot be made from some glass batches, such as the $\mathrm{B} \# 1$ batch containing large grains of feldspar.
At $T_{F O}$, enough glass-forming melt is produced to capture some of the $\mathrm{CO}_{2}$ that continues to evolve. The melt becomes bubbly and the sample volume expands. As temperature increases further, the sample volume reaches maximum, $V_{F M}$, at the foam collapsing temperature, $T_{F M}$, at around $910{ }^{\circ} \mathrm{C}$. Above $T_{F M}$, the batch volume decreases as foam collapses. At $1500{ }^{\circ} \mathrm{C}$, the final melt contains only small secondary bubbles (diameter well below $1 \mathrm{~mm}$ ) that continue to evolve from redox reactions and sulfate decomposition. These small bubbles rise and burst at the surface, leaving behind a low-viscosity glass melt puddle.

Figure 6 illustrates that the foaming curves are similar for both the B\#1 and B\#2 loose batches and for the $\mathrm{B} \# 2$ pellet, although starting from room temperature, the $V / V_{G}$ of pellets is significantly lower than the $V / V_{G}$ of loose batches. This is caused by the difference in the initial sample density, $\sim 2000 \mathrm{~kg} \cdot \mathrm{m}^{-3}$ for pellet and $\sim 1500 \mathrm{~kg} \cdot \mathrm{m}^{-3}$ for loose batch. This difference disappears after the primary foam almost fully collapses

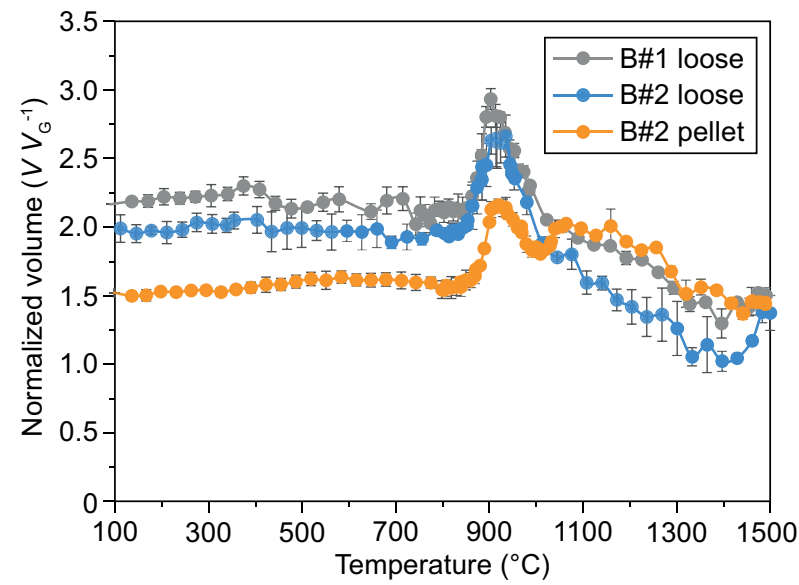

Figure 6. Normalized volume of B\#1 loose batch, B\#2 loose batch, and $\mathrm{B} \# 2$ pellets vs. temp. at heating rate $10 \mathrm{~K} \mathrm{~min}^{-1}$. Error bars display the standard deviation from triplicate measurements.

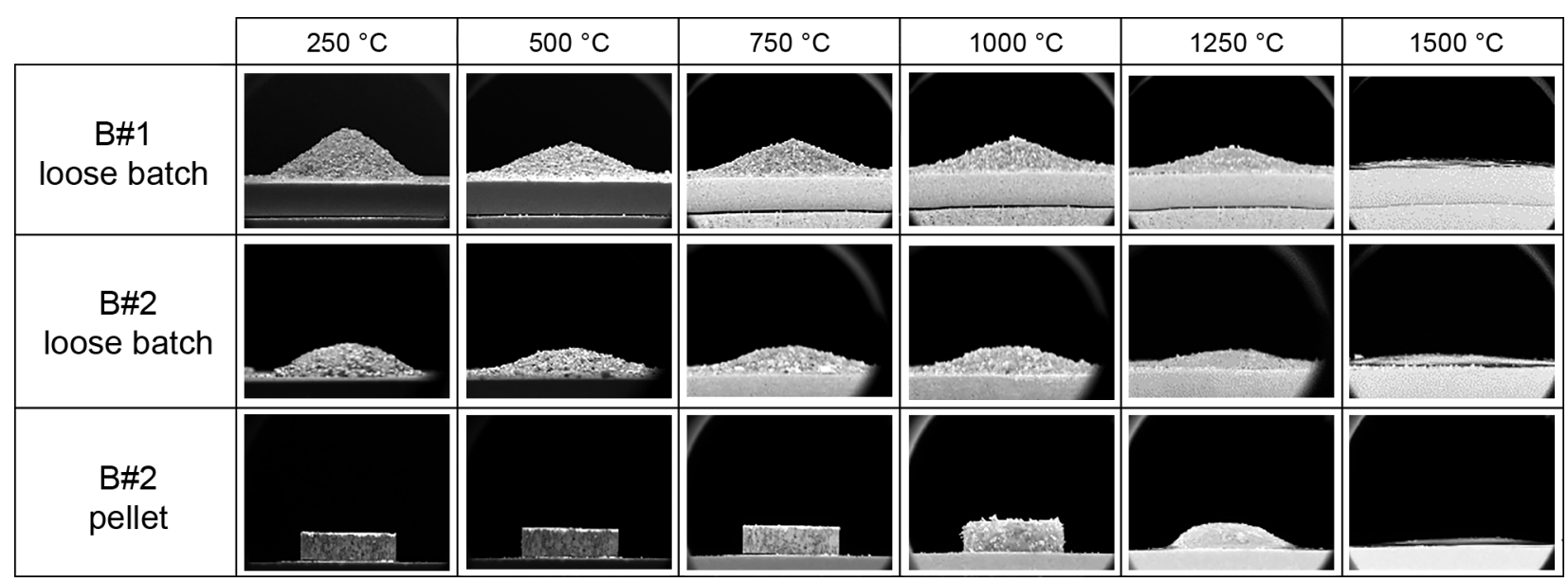

Figure 5. Profiles of loose batch and pellet heated $10 \mathrm{~K} \cdot \mathrm{min}^{-1}$. 
at $\sim 1100{ }^{\circ} \mathrm{C}$, well above $T_{F M}$. Although the maximum normalized volume $V_{\max } / V_{G}$ differs between pellets and loose batches, the foam onset and foam maximum temperatures ( $T_{F O}$ and $T_{F M}$, respectively), and the amount of foam evolved in the foaming interval between $T_{F O}$ and $T_{F M}, \Delta V_{P F} / V_{G}=\left(V_{F M}-V_{F O}\right) / V_{G}$, are all similar. This suggests that the foaming behavior of both the $\mathrm{B} \# 1$ and $\mathrm{B} \# 2$ loose batches and of the B\#2 pellet at the batchmelt interface during HTVO should be similar. Table 3 summarizes the primary foam parameters.

\section{High-temperature visual observation}

Figure 7 shows time sequences of images after batch pellets dropped onto $1350{ }^{\circ} \mathrm{C}$ glass melt in a rectangular silica glass vessel. The proximity of the silica walls and their parallel layout provided high contrast images of primary foam at the batch bottom. The first row displays vigorous foaming of an unpreheated pellet. The following three rows correspond to temperatures to which the pellets were preheated at $10 \mathrm{~K} \cdot \mathrm{min}^{-1}$ before charging onto the glass melt. The calcination temperature used $\left(820^{\circ} \mathrm{C}, 850{ }^{\circ} \mathrm{C}\right.$, and $\left.900{ }^{\circ} \mathrm{C}\right)$ cover the range around the foam onset (see Figure 6).
In each row, the first image corresponds to $t=$ $=0 \mathrm{~s}$, the moment at which the feed pellet landed on the melt surface. With the exception of pellets preheated to $900{ }^{\circ} \mathrm{C}$, the primary foam bubbles immediately started to appear at the interface between the pellet and the melt. The bubbles grew in size, coalesced, and collapsed into cavities - large bubbles that formed below the batch and periodically escaped into the atmosphere around the pellet edges. The cavities were up to $10 \mathrm{~mm}$ thick and up to $15 \mathrm{~mm}$ wide, covering the whole batch bottom (the width of the images in Figure 7 is $\sim 22 \mathrm{~mm}$ ). Over time, the temperature in the entire pellet increased above $T_{F O}$, and the pellet slowly turned into foam that decayed on the melt surface.

This behavior was typical for the non-heat treated pellet and for the pellets heated to $820^{\circ} \mathrm{C}$ and $850{ }^{\circ} \mathrm{C}$. By ideal gas law, the volume of $\mathrm{CO}_{2}$ evolved from $\mathrm{B} \# 2$ batch is approximately $1000 \times$ higher than the volume of produced melt (assuming that all $\mathrm{CO}_{2}$ evolves at $850{ }^{\circ} \mathrm{C}$ and that the glass density is $2500 \mathrm{~kg} \cdot \mathrm{m}^{-3}$ ), and according to TGA and EGA (Figures 3 and 4), a significant fraction of reaction gases still evolves above $850^{\circ} \mathrm{C}$. The behavior at the batch melt interface changed only when the pellets

Table 3. Primary foam parameters - the onset temperature $\left(T_{F O}\right)$, the maximum foam-volume temperature $\left(T_{F M}\right)$, the normalized volume at $T_{F O}\left(V_{F O} / V_{G}\right)$, the maximum normalized volume $\left(V_{F M} / V_{G}\right)$, and the foam amount of $\left(\Delta V_{P F} / V_{G}\right)$.

\begin{tabular}{lcccccc}
\hline & $\Phi$ & $T_{F O}(\mathrm{~K})$ & $T_{F M}(\mathrm{~K})$ & $V_{F O} / V_{G}$ & $V_{F M} / V_{G}$ & $\Delta V_{P F} / V_{G}$ \\
\hline B\#1 loose & 10 & 843 & 903 & 2.10 & 2.93 & 0.83 \\
B\#2 loose & 10 & 844 & 924 & 1.99 & 2.61 & 0.62 \\
B\#2 pellet & 10 & 839 & 919 & 1.60 & 2.16 & 0.56 \\
\hline
\end{tabular}

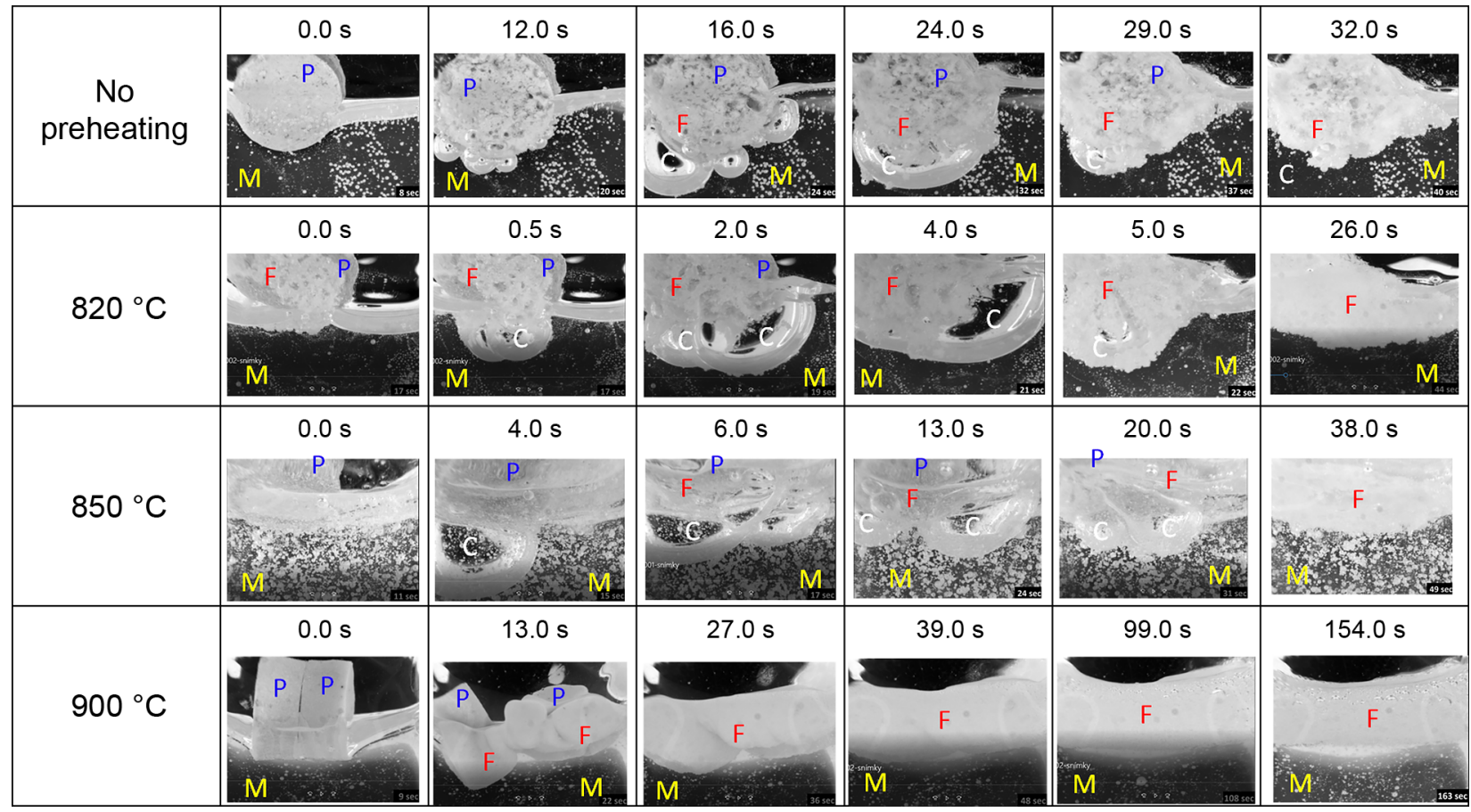

Figure 7. Images of pellet-melt interface captured after charging batch pellets calcined to different temperatures onto glass melt at $1350{ }^{\circ} \mathrm{C}$. 'P' indicates the unreacted pellet(s), ' $\mathrm{F}$ ' the foam layer, ' $\mathrm{C}$ ' the cavities, and ' $\mathrm{M}$ ' the melt (for the $850{ }^{\circ} \mathrm{C}$ test, the melt contained a large number of secondary bubbles). The image width is $\sim 22 \mathrm{~mm}$. 
were preheated to $900{ }^{\circ} \mathrm{C}$, a temperature at which the rapid $\mathrm{CO}_{2}$ evolution subsides. In this case, no vigorous cavity formation was observed at the batch bottom, and the batch pellet slowly turned into foam.

\section{DISCUSSION}

Although analyzing the foaming behavior in an industrial furnace remains impossible, the results obtained by the HTVO confirm the schematic illustrated in Figure 1: a layer of primary foam dwells at the batch-melt interface, releasing gas into cavities that escape through the melt below. Because the melt flow in glass furnaces is relatively sluggish (the melt is quiescent in the silica glass vessel during HTVO), hydrodynamic forces are small, and hydrostatic and surface tension forces control the cavity shape. As observed even below the small pellets, the cavities are elongated bubbles $>15 \mathrm{~mm}$ wide and up to $\sim 10 \mathrm{~mm}$ thick. These results agree with the computational fluid dynamics simulations of foaming at the batch melt-interface performed by Abboud et al. [26], who found that in the case of natural convection, the cavity layer thickness is almost constant, $\sim 7 \mathrm{~mm}$, independent of other parameters such as the amount of gas released during the primary foaming or the shape of the batch layer; these parameters affected only the velocity at which the cavity bubbles (or the gas in cavities) moved sideways below the batch layer.

The HTVO of foaming at the batch melt interface does not only provide a clear visualization of processes occurring at the batch bottom, but has a potential to improve our understanding of the heat transfer from the melt into the batch. The primary foam behaves as a form of insulation barrier, negatively affecting the heat transfer into the batch and thus the melting efficiency. The heat flux, $Q_{B}$, transferred from the melt into the batch at its bottom, is directly linked to the difference between the melt temperature, $T_{M}$, and the temperature at the batch bottom, $T_{B}$, as $Q_{B}=\xi\left(T_{M O}-T_{B}\right)$, where $\xi$ is the heat transfer coefficient [27]. It is also linked to the heat transfer through the foam layer, as $Q_{B}=\lambda / d_{F}\left(T_{B}-T_{F O}\right)$, where $\lambda$ and $d_{F}$ are the primary foam heat conductivity and thickness, respectively [14]

In our recent studies [28-30], we suggest that the dominant factor for the heat transfer into the batch is the so called batch bottom temperature, $T_{B}$, because for most feeds that do not foam excessively, the main resistance to the heat transfer is on the melt side; the foam thickness, $d_{F}$, is a variable that "adjusts" itself to accommodate the heat incoming from the melt. However, we argued that the $T_{B}$ estimated using common laboratory techniques, such as FET, is far from precise, especially because of the differences between in the foam behavior in a heated laboratory sample and at the bottom of the batch in a large glass-melting furnace [12]. We hope that in the future, these in-situ observation techniques, either visual or x-ray, can be improved by using thermocouples to measure the $T_{B}$ and to evaluate the temperature profiles in and below the foam layer at the batch bottom.

\section{CONCLUSIONS}

We used high-temperature visual observation to analyze the behavior and structure of the foam layer that develops at the batch-melt interface during the melting of typical container glass batch. We observed that primary foam bubbles started to form immediately as the batch sample came into contact with molten glass. The primary foam bubbles grew, coalesced, and collapsed into cavities below the batch. The cavities, large flat bubbles up to $10 \mathrm{~mm}$ thick, covered the whole batch sample bottom and periodically escaped around the batch pellet edges. These results well agree with computational fluid dynamics simulations. Because the batch charging was not continuous, the whole pellet sample eventually turned into foam that slowly decayed at the melt surface.

The foaming behavior changed significantly when the batch samples were preheated to temperatures at which the gas evolving reactions during batch conversion, mainly the reactions between soda ash and silica producing $\mathrm{CO}_{2}$, were essentially complete. This prevented the vigorous foaming and the formation of cavities at the batch bottom, and the batch sample slowly turned into foam that slowly coalesced and decayed.

\section{Acknowledgment}

The authors acknowledge financial support by the Czech Science Foundation (project No. 19-14179S). The authors would like to thank Jan Viduna, O-I Czech Republic, a.s., for providing the glass batch samples.

\section{REFERENCES}

1. Mauro J. C., Zanotto E. D. (2014): Two centuries of glass research: historical trends, current status, and grand challenges for the future. International Journal of Applied Glass Science, 5(3), 313-327. doi: 10.1111/ijag.12087

2. Mauro J. C., Philip C. S., Vaughn D. J., Pambianchi M. S. (2014): Glass science in the United States: current status and future directions. International Journal of Applied Glass Science, 5(1), 2-15. doi: 10.1111/ijag. 12058

3. Dubois O., Conradt R. (2004): Experimental study on the effect of cullet and batch water content on the melting behavior of flint and amber container glass batches. Glass science and technology (Frankfurt), 77(3), 137-148.

4. Conradt R., Suwannathada P., Pimkhaokham P. (1994): Local temperature distribution and primary melt formation jn a melting batch heap. Glastech. Ber, 67(5), 103.

5. Xu K., Hrma P., Rice J. A., Schweiger M. J., Riley B. J., Overman N. R., Kruger A. A. (2016): Conversion of nuclear waste to molten glass: cold-cap reactions in crucible tests. Journal of the American Ceramic Society, 99(9), 2964-2970. doi: $10.1111 /$ jace. 14310 
6. Peterson I. M., Shi Y., Ma D., Rygel J. L., Wheaton B., Whitfield P. S., et al. (2019): In situ measurements of reactions in a glass-forming batch by X-ray and neutron diffraction. Journal of the American Ceramic Society, 102(3), 1495-1506. doi: 10.1111/jace.15977

7. Muhlbauer M., Nemec L. (1985). Dissolution of glass sand. American Ceramic Society bulletin, 64(11), 1471-1475.

8. Fedorov, A. G., \& Pilon, L. (2002). Glass foams: formation, transport properties, and heat, mass, and radiation transfer. Journal of Non-Crystalline Solids, 311(2), 154-173. doi: 10.1016/S0022-3093(02)01376-5

9. Kim, D. S., Dutton, B. C., Hrma, P. R., \& Pilon, L. (2006). Effect of furnace atmosphere on E-glass foaming. Journal of non-crystalline solids, 352(50-51), 5287-5295. doi: 10. 1016/j.jnoncrysol.2006.08.035

10. Pilon L. (2012). Foam Engineering: Fundamentals and Applications, P. Stevenson, (Ed.) John Wiley \& Sons, Incorporated: Somerset, United Kingdom.

11. Pokorny R., Hilliard Z. J., Dixon D. R., Schweiger M. J., Guillen D. P., Kruge, A. A., Hrma P. (2015): Onedimensional cold cap model for melters with bubblers. Journal of the American Ceramic Society, 98(10), 3112-3118. doi: 10.1111 jace. 13775

12. Luksic S. A., Pokorny R., George J., Hrma P., Varga T., Reno L. R., et al. (2020): In situ characterization of foam morphology during melting of simulated waste glass using X-ray computed tomography. Ceramics International, 46(11), 17176-17185. doi: 10.1016/j.ceramint.2020.02.215

13. Hrma P., Klouzek J., Pokorny R., Lee S. M., Kruger A. A. (2019): Heat transfer from glass melt to cold cap: gas evolution and foaming. Journal of the American Ceramic Society, 102(10), 5853-5865. doi: 10.1111/jace.16484

14. Lee S., Hrma P., Pokorny R., Klouzek J., VanderVeer B. J., Dixon D. R., et al. (2017): Effect of melter feed foaming on heat flux to the cold cap. Journal of nuclear materials, 496, 54-65. doi: 10.1016/j.jnucmat.2017.09.016

15. Harris W. H., Guillen D. P., Klouzek J., Pokorny R., Yano T., Lee S., et al. (2017): X-ray tomography of feed-to-glass transition of simulated borosilicate waste glasses. Journal of the American Ceramic Society, 100(9), 3883-3894. doi: 10.1111 jace. 14895

16. Boloré D., Gibilaro M., Massot L., Chamelot P., Cid E., Masbernat O., Pigeonneau F. (2020): X-ray imaging of a high-temperature furnace applied to glass melting. Journal of the American Ceramic Society, 103(2), 979-992. doi: 10.1111/jace.16809

17. Luksic S. A., Pokorny R., Hrma P., Varga T., Rivers E. L., Buchko A. C., et al. (2021): Through a glass darkly: In-situ $\mathrm{X}$-ray computed tomography imaging of feed melting in continuously fed laboratory-scale glass melter. Ceramics International, 47(11), 15807-15818. doi: 10.1016/j.ceramint.2021.02.153

18. Lee S. M., Hrma P., Pokorny R., Traverso J. J., Klouzek J., Schweiger M. J., Kruger A. A. (2019): Heat transfer from glass melt to cold cap: effect of heating rate. International Journal of Applied Glass Science, 10(3), 401-413. doi: 10.1111/ijag.13104
19. Ueda N., Vernerová M., Kloužek J., Ferk1 P., Hrma P., Yano T., Pokorný R. (2021): Conversion kinetics of container glass batch melting. Journal of the American Ceramic Society, 104(1), 34-44. doi: 10.1111/jace.17406

20. Ferkl P., Hrma P., Kloužek J., Vernerová M., Kruger A., Pokorný R. (2021): Model for batch-to-glass conversion: coupling the heat transfer with conversion kinetics. Journal of Asian Ceramic Societies, 9(2), 652-664. doi: 10.1080/ 21870764.2021.1907914

21. Pokorný R., Hrma P., Lee S., Klouzek J., Choudhary M. K., Kruger A. A. (2020): Modeling batch melting: Roles of heat transfer and reaction kinetics. Journal of the American Ceramic Society, 103(2), 701-718. doi: 10.1111/jace.16898

22. Beerkens R.G.C., et al. (2002). Melting and Fining, in Mathematical Simulation in Glass Technology. Schott Series on Glass and Glass Ceramics (Science, Technology, and Applications). Loch H., Krause D., (Eds.), Springer: Berlin, Heidelberg, Germany.

23. Hilliard Z., Hrma P. (2016): A method for determining bulk density, material density, and porosity of melter feed during nuclear waste vitrification. Journal of the American Ceramic Society, 99(1), 98-105. doi: 10.1111/jace.13919

24. Hujova M., Pokorny R., Klouzek J., Lee S., Traverso J. J., Schweiger M. J., et al. (2018): Foaming during nuclear waste melter feeds conversion to glass: Application of evolved gas analysis. International Journal of Applied Glass Science, 9(4), 487-498.doi: 10.1111/ijag.12353

25. Oates J.A.H. (1998). Lime and Limestone. Weinheim (Germany): Wiley-VCH.

26. Abboud, A.W., et al. (2020). Numerical Experiments of the Cavity Layer underneath the Cold Cap in a Waste Glass Melter. In: Advances in Thermal Hydraulics (ATH '20). 2020. Palaiseau, France: American Nuclear Society.

27. Hrma P., Pokorny R., Lee S., Kruger A. A. (2019): Heat transfer from glass melt to cold cap: melting rate correlation equation. International Journal of Applied Glass Science, 10(2), 143-150. doi: 10.1111/ijag.12666

28. Lee S., Cutforth D. A., Mar D., Klouzek J., Ferkl P., Dixon D. R., et al. (2021): Melting rate correlation with batch properties and melter operating conditions during conversion of nuclear waste melter feeds to glasses. International Journal of Applied Glass Science, 12(3), 398-414. doi: 10.1111/ijag.15911

29. Lee S. M., McCarthy B. P., Hrma P., Chun J., Pokorny R., Klouzek J., Kruger A. A. (2020): Viscosity of glassforming melt at the bottom of high-level waste melter-feed cold caps: Effects of temperature and incorporation of solid components. Journal of the American Ceramic Society, 103(3), 1615-1630. doi: 10.1111/jace.16876

30. Lee S., Ferkl P., Pokorny R., Klouzek J., Hrma P., Eaton W. C., Kruger A. A. (2020): Simplified melting rate correlation for radioactive waste vitrification in electric furnaces. Journal of the American Ceramic Society, 103(10), 5573-5578. doi: $10.1111 /$ jace. 17281 